\title{
AIDS-related lymphomas in Nigeria an emerging phenomenon
}

\author{
L Salawu ${ }^{1 *}$, RA Bolarinwa ${ }^{1}$, OO Lawal ${ }^{2}$, AA Oyekunle ${ }^{1}$, O Adeodu $^{3}$, EA Adejuyigbe ${ }^{3}$, KA Adelusola ${ }^{4}$, NO Akinola ${ }^{1}$, \\ MA Ndakotsu', MA Durosinmi ${ }^{1}$
}

From $12^{\text {th }}$ International Conference on Malignancies in AIDS and Other Acquired Immunodeficiencies (ICMAOI)

Bethesda, MD, USA. 26-27 April, 2010

\section{Background}

In comparison to the western world, aggressive nonHodgkin's lymphoma (NHL) including primary central nervous system (CNS) lymphoma, as AIDS-defining disease, is less common in sub-Saharan Africa even with its high HIV/AIDS prevalence. We studied the occurrence of HIV/AIDS-related lymphomas in Nigerian patients with a view toward highlighting the incidence.

\section{Patients and method}

Consecutive cases of histologically and/or cytologically confirmed lymphoma screened for HIV (after appropriate counseling) and seen between January 2003 and December 2009 were the subjects. Types and treatment outcome of lymphoma in the HIV-positive group were further studied. Data were analyzed using appropriate descriptive and inferential statistics.

\section{Results}

There were 161 cases comprising NHL, 42 (25.5\%); HL, 15 (9.3\%), and BL, 104, (64.6\%). Seven (4.3\%), aged 2-49 (median $=41)$ years were retroviral positive. Of these, 4 ( 3 males, 1 female, aged $28-49$ (median $=38.5)$ years) had NHL, 2 (both females) HL, and 1 case, a 2-year-old boy with HIV since birth, had Burkitt's and an HIVpositive mother. All, except one female with stage $1 \mathrm{HL}$, presented late (at least clinical stage IIIb). Three patients with NHL and 1 with late-stage HL succumbed to their disease within 1-3 weeks of hospital admission. The remaining 3 patients had been responding satisfactorily

\footnotetext{
*Correspondence: Isalawu2002@yahoo.co.uk

'Department of Haematology, Obafemi Awolowo University Teaching

Hospitals Complex, lle-lfe, Nigeria

Full list of author information is available at the end of the article
}

to chemotherapy (CHOP for NHL, ABVD for HL, and COM for Burkitt's lymphoma.)

\section{Conclusion}

Compared to earlier reports from Nigeria, the AIDSrelated lymphomas rate of $4.3 \%$ in the series indicated rising incidence. AIDS-associated BL of $0.1 \%$, in spite of high background prevalence of Burkitt's lymphoma ( $>60 \%$ of lymphomas), supported its relative rarity. With longer survival and longer immunosuppression, closely following up AIDS patients on HAART would be justified, as more cases of AIDS-related lymphomas may possibly emerge in the future.

\section{Acknowledgements}

AIDS-Associated Malignancies Management Team, OAUTHC ILE-IFE Nigeria. This article has been published as part of Infectious Agents and Cancer Volume 5 Supplement 1, 2010: Proceedings of the $12^{\text {th }}$ International Conference on Malignancies in AIDS and Other Acquired Immunodeficiencies (ICMAOI). The full contents of the supplement are available online at http://www.biomedcentral.com/1750-9378/5?issue=S1.

\section{Author details}

'Department of Haematology, Obafemi Awolowo University Teaching Hospitals Complex, Ile-lfe, Nigeria. ${ }^{2}$ Department of Surgery, Obafemi Awolowo University Teaching Hospitals Complex, lle-lfe, Nigeria. ${ }^{3}$ Department of Paediatrics, Obafemi Awolowo University Teaching Hospitals Complex, lle-Ife, Nigeria. ${ }^{4}$ Department of Morbid Anatomy, Obafemi Awolowo University Teaching Hospitals Complex, lle-lfe, Nigeria.

Published: 11 October 2010

doi:10.1186/1750-9378-5-S1-A3

Cite this article as: Salawu et al:: AIDS-related lymphomas in Nigeria an emerging phenomenon. Infectious Agents and Cancer 2010 5(Suppl 1):A3. 